\title{
FÓRUM
}

Submetido 28.06.2019. Aprovado 02.12.2019

Avaliado pelo sistema double blind review. Editores científicos convidados: Diego M. Coraiola, Amon Barros, Mairi Maclean e Willian M. Foster

Versão traduzid

DOI: http://dx.doi.org/10.1590/So034-759020210104

\section{SEQUESTRADO PELA ESPERANÇA: DINÂMICAS DE DESVIO DA MISSÃO E DISSOLUÇÃO DE IDENTIDADE EM UMA ORGANIZAÇÃO SEM FINS LUCRATIVOS}

\author{
Hijacked by hope: dynamics of mission drift and identity dilution in a nonprofit \\ organization
}

\author{
Secuestrado por la esperanza: Dinámicas de disolución identitaria y desviación \\ de la misión en una organización sin fines de lucro
}

\begin{abstract}
RESUMO
Este artigo aborda como a identidade e missão organizacionais são construídas e reproduzidas ao longo do tempo por meio de processos de lembrança e esquecimento. Com base na literatura sobre memória organiza cional, em uma perspectiva de recurso estratégico, o artigo apresenta os efeitos da história, da memória e do passado que permitiram a resiliência e a sobrevivência organizacional. Enquanto narrativas temporais podem ser aplicadas como ferramentas retóricas para construir a coerência entre passado, presente e futuro, descobrimos que elas também têm o potencial de "derivar" e "sequestrar" a direção organizacional. 0 presente estudo mostra como um foco excessivo no futuro causa desvio de missão e ambiguidade de identidade. Con tudo, a ambiguidade de identidade é resolvida revisitando e lembrando o passado. 0 passado organizacional não é apenas um recurso estratégico para a construção da identidade, mas uma âncora temporal a partir da qual a organização pode redescobrir seu propósito original. Os resultados são baseados em um estudo de caso qualitativo, aprofundado e etnográfico de uma organização sem fins lucrativos com o objetivo de estabelecer uma rede nacional de hortas em escolas locais.
\end{abstract}

PALAVRAS-CHAVE | Identidade organizacional, memória coletiva, narrativa histórica, foco temporal, organização sem fins lucrativos.

\begin{abstract}
This article addresses how organizational identity and mission are constructed and reproduced over time through processes of remembering and forgetting. Building on literature that views organizational memory as a strategic resource, this paper showcases the enabling effects of history, memory, and the past for organizational resilience and survival. Although temporal narratives may be employed as rhetorical tools to construct coherency between the past, present, and future, we find they also have the potential of sidetracking and hijacking an organization's direction. Our study shows how an excessive focus on the future can cause mission drift and identity dilution. However, the identity dilution can be adressed through revisiting and remembering the past. The organizational past is not merely a strategic resource for identity construction, it is also a temporal anchor from which the organization may rediscover its original purpose. The findings are based on a qualitative, in-depth, ethnographic case study of a nonprofit organization whose goal is to establish a national network of local school gardens.
\end{abstract}

KEYWORDS / Organizational identity, organizational memory, historical narrative, temporal focus, nonprofit organization

SOPHIE MARIE CAPPELEN ${ }^{1}$

smc.ioa@cbs.dk

0000-0002-0875-243X

\section{JESPER STRANDGAARD PEDERSEN ${ }^{1}$}

js.ioa@cbs.dk

0000-0002-2332-5540

Copenhagen Business School, Department of Organization, Frederiksberg, Dinamarca

\section{RESUMEN}

Este artículo aborda cómo la identidad y la misión organizativa se construyen y se reproducen a lo largo del tiempo a través de procesos de recuerdo y olvido. Con base en la literatura sobre memoria organizacional, a través de una perspectiva de recurso estratégico, el artículo presenta los efectos de la historia, de la memoria y del pasado que permitieron la resiliencia y la supervivencia organizacional. Mientras que las narraciones temporales se pueden aplicar como herramientas retóricas para construir la coherencia entre pasado, presente y futuro, descubrimos que ellas también tienen el potencial de "desviar" y "secuestrar" la dirección organizacional. El presente estudio muestra cómo un enfoque excesivo en el futuro causa desviación de misión y ambigüedad de identidad. Sin embargo, la ambigüedad de identidad se resuelve al revisar y recordar el pasado. El pasado organizacional no es sólo un recurso estratégico para la construcción de la identidad, sino un ancla temporal a partir de la cual la organización puede redescubrir su propósito original. Los resultados se basan en un estudio de caso cualitativo en profundidad y etnográfico de una organización sin fines de lucro con el objetivo de establecer una red nacional de huertos en escuelas locales.

PALABRA CLAVE / Identidad organizacional, memoria organizacional, narrativa histórica, enfoque temporal, organización sin fines de lucro. 
"It puzzles me sometimes... Why look back at what has been done for more than a hundred years? Why not look forward and say what could be fantastic?"

(Chair and Nonprofit founder)

\section{INTRODUÇÃO}

As maneiras como os mecanismos de memória moldam a construção da identidade organizacional ao longo do tempo recentemente passou a ser uma área fundamental de interesse entre autores da área organizacional (por exemplo, Anteby \& Molnár, 2012; Foster, Coraiola, Suddaby, Kroezen, \& Chandler, 2017; Schultz \& Hernes, 2013). Essa corrente de pesquisa enfatizou as bases temporais da construção da identidade em que a experiência vivenciada é mobilizada no presente para projetar a direção futura da organização (Ezzy, 1998). Ao chamar a atenção para a agência temporal das organizações (Emirbayer \& Mische, 1998), este artigo destaca a plasticidade da identidade organizacional e como as identidades estão sujeitas a mudanças contínuas (Kreiner, Hollensbe, Sheep, Smith, \& Kataria, 2015). Nós nos baseamos em pesquisas anteriores que veem a construção da identidade como um processo de desdobramento em que buscas são realizadas em resposta a eventos, transições e pontos de inflexão (Maclean, Harvey, Gordon, \& Shaw, 2015). Resultados anteriores mostram como as organizações direcionam sua atenção para o passado para mobilizar memórias do presente para o futuro (Schultz \& Hernes, 2013). Embora essas descobertas indiquem que o foco temporal - o grau em que as organizações tendem a direcionar e focar sua atenção no passado, presente e/ ou futuro - importa, o papel que o foco temporal desempenha na construção da identidade permaneceu em grande parte implícito.

Trazendo essa questão para o primeiro plano, esse estudo investiga os mnemônicos da construção da identidade, mostrando como as organizações devem equilibrar a adaptação contínua às mudanças nas condições ambientais ao mesmo tempo em que permanecem fiéis a si mesmas. Achados anteriores mostram como as organizações, consciente ou inconscientemente, selecionam ou omitem elementos históricos específicos de suas narrativas a fim de promover uma determinada identidade e direção rumo ao futuro (por exemplo, Foster, Suddaby, Minkus, \& Wiebe, 2011; Hatch \& Schultz, 2017; Rowlinson, Casey, Hansen, \& Mills, 2014). Portanto, a memória organizacional pode não apenas facilitar a mudança, mas também criar um senso de continuidade da identidade (Anteby \& Molnár, 2012). Partindo dessa visão, argumentamos que a capacidade de uma organização de alavancar e empregar tais memórias depende de sua capacidade de mudar continuamente o foco temporal.
Enfatizando a dimensão temporal da identidade organizacional, fazemos a seguinte pergunta: Como o foco temporal molda os processos de construção da identidade organizacional?

Para responder a essa pergunta, nos baseamos em um estudo de caso qualitativo de uma organização sem fins lucrativos. Mostramos como uma série de incidentes e ações resultam na perda de memória organizacional e no desenvolvimento de um enfoque temporal unilateral no futuro. Esse processo é impulsionado por uma preocupação exagerada com o desenvolvimento para concretizar um "futuro esperado", o que, por sua vez, tem consequências para a identidade organizacional. Argumentamos que o esquecimento organizacional pode levar à produção de narrativas de identidade fracamente acopladas que sequestram e deslocam a identidade e missão organizacional original. A alta rotatividade de funcionários e as pressões de benfeitores externos, dos quais a organização depende financeiramente para continuar operando, alimentam ainda mais esse processo. Consequentemente, essas condições precárias induzem um foco excessivo em projetos orientados para o futuro e uma menor atenção às operações passadas e presentes. Por estar excessivamente preocupada em agradar os stakeholders externos, a organização gera um vácuo da identidade por meio do qual uma narrativa organizacional recém-construída se torna uma ferramenta de remendo para construir coerência entre projetos novos e projetos em andamento. No entanto, nosso estudo também mostra que as narrativas de identidade podem ser reequilibradas quando os esforços são direcionados a revisitar e lembrar o passado. Nossos achados expandem e contribuem para a abordagem social construtivista da memória, que atualmente se concentra principalmente nos processos intraorganizacionais (Mena, Rintamäki, Fleming, \& Spicer, 2016). As discussões anteriores sobre o esquecimento coletivo eram focadas em um amplo número de questões, tanto positivas quanto negativas, em relação à identidade organizacional (Easterby-Smith \& Lyles, 2011). Embora reconheçamos que o esquecimento pode encorajar a manutenção e estabilidade da identidade (Anteby \& Molnár, 2012), argumentamos que a perda de memória organizacional também pode levar ao desvio da missão organizacional e diluição da identidade. 0 conceito de “diluição" origina-se dos estudos da teoria do Direito sobre marcas, a qual "tal como concebida originalmente, referia-se ao dano que ocorre quando uma marca famosa e distinta perde seu sentido singular" (Dogan, 2006, p. 103). Frank Schechter, que cunhou o termo em 1927 (Bone, 2007), definiu diluição como "o apagamento gradual ou dispersão da identidade e controlar a opinião pública sobre a marca ou nome pelo seu uso em bens não concorrentes" (Schechter, 1927, recuperado de Dogan, 2006, p. 103). 


\section{Narrativas de identidade temporal}

A interação entre temporalidade organizacional e identidade é um campo de crescente interesse acadêmico. Esse campo de pesquisa examina como as organizações se envolvem com seu passado, presente e futuro como uma forma de construir sua identidade (por exemplo, Foster et al., 2011; Hatch \& Schultz, 2017; Schultz \& Hernes, 2013). Apesar de seu caráter de permanência e resistência (Albert \& Whetten, 1985), a identidade gradualmente emergiu como um conceito dinâmico. Como as narrativas de identidade descrevem um tempo vivido e contínuo, elas estão "em andamento e inacabadas, sendo continuamente feitas e refeitas à medida que os episódios acontecem" (Ezzy, 1998, p. 247). À medida que as organizações se valem da experiência vivenciada no presente para projetar sua identidade no futuro, a identidade organizacional pode, portanto, ser considerada um processo de construção e mudança contínua (Kreiner et al., 2015).

Estudos anteriores já observaram como os atores organizacionais se envolvem no trabalho temporal ao mobilizar memórias organizacionais para orientar a construção contínua de identidades no presente e no futuro (Cappelen \& Strandgaard Pedersen, 2020; Maclean, Harvey, Sillince, \& Golant, 2018; Schultz \& Hernes, 2013). Definimos memória organizacional como uma forma de memória coletiva, consistindo em artefatos mentais e estruturais embutidos e distribuídos em diferentes níveis e estruturas dentro e além da organização (Walsh \& Ungson, 1991). Essa compreensão da memória coletiva pressupõe que a memória de grupo existe e vive além da lembrança individual. As memórias não são vistas como um repositório de experiências passadas, mas sim como imagens que são ativadas em contextos sociais específicos (Halbwachs, 1992). Portanto, a memória organizacional está intimamente ligada à identidade organizacional uma vez que os grupos se constituem no processo de lembrança quando o passado é refeito para fins coletivos atuais (Olick \& Robbins, 1998).

0 ato de atribuir significado particular no presente a eventos passados foi conceituado como "lembrança organizacional" e é definido como "o processo pelo qual os atores usam a retórica e a história para construir socialmente a adesão a uma organização" (Suddaby et al., 2016, p. 298). Usando ferramentas retóricas e narrativas discursivas, os atores organizacionais criam valores compartilhados com base na memória compartilhada, a fim de construir uma identidade comum ancorada em um passado comum socialmente construído. Nessas tentativas de uso do passado, as organizações empregam traços mnemônicos e narrativas como matéria-prima a partir da qual a identidade é posteriormente montada. Para isso, os atores contam com tecnologias mnemônicas, tais como símbolos como formas de memória material e narrativas compartilhadas, para enquadrar e substanciar o que é lembrado coletivamente (Lippmann \& Aldrich, 2016; Schultz \& Hernes, 2013). Portanto, a forma como as organizações se identificam está "íntima e intrincadamente conectada com as histórias que adotaram a respeito do caminho que percorreram até o presente" (Heisler, 2008, p. 15) e para onde se imaginam caminhando no futuro.

\section{Trabalho de memória organizacional}

Embora em um estado de fluxo, as identidades organizacionais podem se apresentar estáveis (Anteby \& Molnár, 2012). Os gerentes podem interferir na memória organizacional ao omitir repetidamente elementos contraditórios da narrativa organizacional preferida, como Anteby e Molnár (2012) retrataram em seu estudo de uma empresa aeroespacial francesa. Por meio do uso estratégico de narrativas históricas, as organizações também podem construir demarcações entre o passado e o presente para promover a mudança de identidade. Ybema (2010) argumentou que os atores organizacionais podem alterar a identidade organizacional ao se envolverem em conversas descontínuas temporalmente. No caso de um jornal nacional holandês, os atores organizacionais possibilitaram a mudança da identidade ao construir fortes contrastes entre o antigo e o novo por meio de narrativas e histórias organizacionais. Esses exemplos ilustram como o uso intencional de narrativas e recursos discursivos desempenha um papel importante na formação e mudança da identidade. Por meio da repetição, as narrativas temporais ganham destaque ao longo do tempo, contribuindo para a estabilidade da identidade organizacional e dos significados que os indivíduos compartilham em relação ao passado organizacional (Dailey \& Browning, 2014). Em seu estudo sobre uma transição organizacional na Procter \& Gamble, Maclean et al. (2018) verificaram que a retórica e a narrativa organizacional eram usadas tanto como uma âncora ou pedra de toque do passado quanto como uma ferramenta para preparar a organização para mudanças futuras. Desse modo, as narrativas são tanto geradoras quanto performativas (Maclean et al., 2015), pois as histórias (re)contadas e lembradas fornecem às organizações roteiros de ação para o futuro (Bluedorn, 2002).

Enquanto as discussões sobre memória organizacional tendem a enfatizar a lembrança, o esquecimento organizacional é um aspecto igualmente importante da memória. 0 conceito denota a inexistência de uma versão compartilhada do passado, que surge em decorrência da "ausência de memória institucionalizada" (Fine, 2012, p. 59). Embora algum esquecimento organizacional ocorra 
como resultado da alta rotatividade de funcionários (EasterbySmith \& Lyles, 2011) ou processos inconscientes de inércia ao longo do tempo (Walsh \& Ungson, 1991), o esquecimento coletivo também pode resultar do "esquecimento do trabalho" de forma deliberada, ativa e instrumental" (Mena et al., 2016). Como o esquecimento depende do contexto, suas consequências podem ser tanto positivas quanto negativas (Holan \& Phillips, 2004). Os estudos que ilustram os resultados organizacionais positivos do esquecimento postulam que o esquecimento fortalece a capacidade da organização de promover disrupção e inovar, promove mudança e renovação e reduz a perda de moral após o fracasso (Wilkins \& Bristow, 1987). Outros estudos sugerem que o esquecimento seletivo também pode ajudar na manutenção da identidade (Anteby \& Molnár, 2012; Ybema, 2010) ou permitir que as organizações se distanciem de um passado que é considerado ilegítimo no presente (Booth, Clark, Delahaye, Procter, \& Rowlinson, 2007). Outros estudos mostram como o esquecimento induz as comunidades mnemônicas a se tornarem mais atentas às mudanças ambientais e, portanto, mais aptas a se desenvolver e se ajustar de acordo com o ambiente em constante mudança (Blaschke \& Schoeneborn, 2006). Mudando o foco para as consequências negativas do esquecimento, esses estudos geralmente giram em torno de questões relacionadas ao conhecimento organizacional e aprendizagem (por exemplo, Madsen, 2009) (ou a falta dele) (por exemplo, Brunsson, 2009; Holan \& Phillips, 2004) e perda ou silenciamento da identidade (por exemplo, Albert \& Whetten, 1985; Maclean, Harvey, \& Stringfellow, 2017). Portanto, para evitar a perda de memória, as organizações devem se esforçar para manter "um vínculo contínuo com seus 'veteranos' para garantir adequada aquisição de memória e processos de recuperação controlados" (Walsh \& Ungson, 1991, p. 78).

\section{Agência temporal e foco na construção da identidade}

A noção de identidade como sendo processual, por meio da qual as memórias da experiência vivenciada são continuamente integradas à narrativa de identidade, pressupõe que as organizações recorrem a memórias passadas e imaginários futuros para construir e visualizar sua identidade. Isso implica um nível de agência na maneira como as organizações constroem e fazem uso do passado e do futuro imaginado em sua contínua construção de identidade. Emirbayer e Mische (1998) cunharam a frase “a tríade cordial” para descrever as modalidades temporais de passado, presente e futuro, que são concepções temporais vistas como emaranhadas (Reinecke \& Ansari, 2016). Enquanto as concepções temporais denotam as propriedades que as organizações atribuem ao tempo (ou seja, passado-presente-futuro), as orientações temporais referem-se ao valor que é dado ao tempo (Kunisch, Bartunek, Mueller, \& Huy, 2017). As orientações temporais são distintas, mas ainda assim relacionadas ao foco temporal, que se refere ao grau em que as organizações tendem a direcionar e focar sua atenção no passado, presente ou futuro (ou uma combinação desses). Organizações com orientação e foco temporal no passado tendem a atribuir maior valor e prioridade a eventos passados (Clark \& Collins, 1993), enquanto orientação e foco no futuro enfatizam e valorizam o que está por vir (Bluedorn, 2002; Maclean et al., 2018). De igual modo, as organizações com foco dominante no presente priorizam o aqui e agora em suas ações e correm o risco de se tornarem vítimas do curto prazo (Marginson \& McAulay, 2008).

Embora poucos estudos discutam explicitamente como o foco temporal molda a identidade organizacional, algumas pesquisas discutiram como o foco temporal influencia a estratégia (Kunisch et al., 2017). Alguns autores argumentam que as organizações que possuem foco temporal no passado tendem a ser menos adaptáveis e mais avessas a novas experiências. Essas organizações têm menos probabilidade de iniciar mudanças estratégicas ou introduzir novos produtos do que aquelas caracterizadas por foco temporal mais forte no presente ou no futuro (Nadkarni \& Chen, 2014). Outros autores constataram que o foco temporal no presente influencia as organizações a enfatizar metas imediatas, adjacentes e de curto prazo (Marginson \& McAulay, 2008), enquanto o foco temporal no passado pode melhorar o aprendizado organizacional e a tomada de decisão (Shipp, Edwards, \& Lambert, 2009). Argumentamos que o foco temporal é fundamental para a construção da identidade organizacional. No entanto, ele foi amplamente negligenciado em pesquisas anteriores. Enquanto estudos anteriores mostram como as organizações mobilizam memórias e visões para construir suas identidades (Schultz \& Hernes, 2013), a maneira pela qual elas se deslocam entre os focos temporais nesse processo permaneceu em grande parte implícita (Corley \& Gioia, 2004). Trazemos esse mecanismo para o primeiro plano, mostrando como um foco temporal desequilibrado no futuro pode levar à diluição da identidade. Argumentamos que a diluição da identidade resulta de uma falha em integrar continuamente a experiência vivenciada (isto é, memória organizacional) na narrativa da identidade temporal. Finalmente, demonstramos como uma mudança contínua no foco temporal (entre o passado, o presente e o futuro) permite que as organizações restaurem o equilíbrio identitário. 


\section{O ESTUDO}

\section{Contexto do ambiente de pesquisa}

Para esse estudo, conduzimos um estudo de caso empírico em uma organização sem fins lucrativos cujo objetivo é estabelecer uma rede nacional de hortas escolares de culinária. A horta escolar é promovida como uma "sala de aula alternativa" e tem demonstrado fortalecer competências alimentares e sociais, saúde e consciência ambiental das crianças (Wistoft, 2013). Como tal, a organização tem o potencial de formar crianças com mais conhecimento sobre alimentos e comunidades locais sustentáveis por meio de seu conceito educacional. A organização opera em um contexto no qual as organizações sem fins lucrativos têm desempenhado um papel social substancial desde que a "liberdade de associação" passou a fazer parte da constituição democrática dinamarquesa em 1848 (Henriksen, Strømsnes, \& Svedberg, 2018). Após o avanço do estado de bem-estar social após a Segunda Guerra Mundial, caracterizado por disposições sociais financiadas por impostos e uma redistribuição da renda baseada em impostos progressivos, as organizações sem fins lucrativos dinamarquesas começaram gradualmente a assumir seu papel como organizações de interesse (Henriksen \& Bundesen, 2004). Como o modelo de bem-estar social foi pressionado no final da década de 1980, o governo passou a depender cada vez mais do setor sem fins lucrativos para fornecer serviços de bemestar suplementares. Nas políticas desenvolvidas em meados da década de 1990, foi recomendado que as organizações sem fins lucrativos deveriam aliviar a pressão crescente sobre o bem-estar público, agindo "como empreendedores para enfrentar os problemas sociais emergentes" (Henriksen et al., 2018, p. 17). Embora o setor sem fins lucrativos tenha ganhado destaque, os recursos públicos para financiar suas operações têm diminuído lentamente. Para preencher essa lacuna, as fundações industriais privadas assumiram um papel de destaque na garantia de operação contínua de organizações sem fins lucrativos dinamarquesas. Em 2017, as fundações industriais doaram mais de $€ 2,3$ bilhões (DKK 17,25 bilhões) ao setor (Kraft \& Partners, 2019). Essa mudança também significou uma reorganização do setor sem fins lucrativos, o qual é caracterizado por organizações baseadas em projetos e esquemas de financiamento de curto prazo.

\section{Coleta e análise de dados}

Os resultados são baseados em um estudo de caso aprofundado realizado durante 2016-2019. Os dados provem de várias fontes incluindo dados de arquivo (documentos organizacionais, páginas da web, relatórios, etc.) e materiais divulgados em mídias públicas (recortes de notícias, etc.). Além disso, os participantes foram observados amplamente no local (reuniões, eventos de horta escolar, seminários, etc.). Os resultados desse estudo são em grande parte extraídos de dados observacionais (150 horas) coletados ao longo de três anos. Nesse período, organizamos e realizamos um total de dezoito workshops, de aproximadamente quatro horas cada, em colaboração com membros da equipe de gestão da organização sem fins lucrativos. Essas reuniões tinham uma dupla função: primeiro, adquirir conhecimentos sobre a organização e seus antecedentes, contexto e desenvolvimentos; e, posteriormente, gerar dados específicos sobre como os membros da organização veem coletivamente a missão, visão, estratégia, identidade, cultura e imagem organizacional (Hatch \& Schultz, 2002). Ao considerarmos que a construção da identidade ocorre por meio do diálogo, da linguagem e das narrativas, as oficinas também representaram uma oportunidade para observar e notar como as memórias e os imaginários organizacionais foram colocados em jogo no contexto de grupo (Olick, 1999). As oficinas possibilitaram o acesso regular às organizações, o que nos permitiu acompanhar de perto o desenvolvimento contínuo da narrativa da identidade organizacional. As oficinas também forneceram oportunidades para capturar fotos e fazer anotações extensas.

Para complementar nosso material de observação, um total de vinte e cinco entrevistas foram realizadas. Sete entrevistas foram realizadas com a organização principal (uma entrevista foi realizada com o fundador da organização e atual presidente do conselho e seis entrevistas foram realizadas com membros da secretaria da organização e equipes de gestão). Além disso, treze hortas escolares locais foram visitadas e durante as visitas foram realizadas entrevistas com representantes de hortas escolares locais. Essas entrevistas foram realizadas individualmente ou em grupo e duraram entre uma e duas horas. Durante as entrevistas, buscamos estimular a lembrança e o compartilhamento de “memórias de lampejo" (Brown \& Kulik, 1977): memórias que surgem após um acontecimento surpreendente ou resultante que as pessoas percebem como decisivo. Também investigamos estruturas de memória mais estáveis, baseadas em narrativas organizacionais predominantes (Boje, 2008). Ao questionar a memória de nossos informantes, consideramos com cautela a dependência que tais lembranças tem de pistas, já que a capacidade de lembrar é "obviamente altamente dependente de uma série de fatores contextuais, fatores esses que estão sempre em fluxo" (Olick, 1999, p. 340). Para limitar os efeitos da dependência de pistas, as perguntas foram feitas de forma e maneira aberta para evitar o direcionamento do processo de 
rememoração para corresponder às nossas ideias preconcebidas de eventos organizacionais decisivos. Por fim, cinco entrevistas foram realizadas com representantes de cinco fundações que operam em diferentes setores para subsidiar o contexto organizacional das organizações sem fins lucrativos. O Quadro 1 apresenta uma visão geral dos dados.

\section{Quadro 1. Visão geral dos dados}

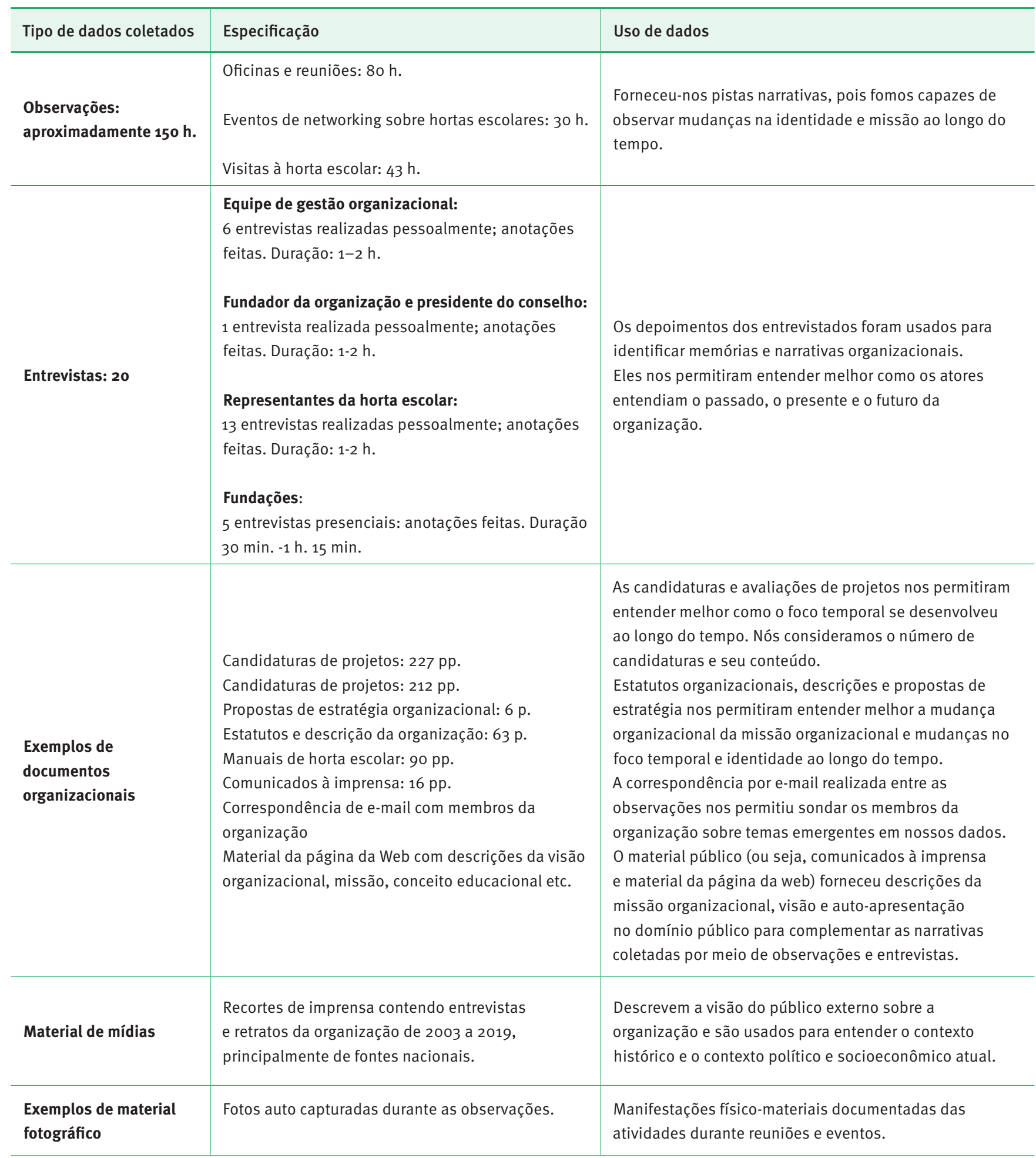


Todas as entrevistas foram transcritas e enviadas aos entrevistados para controle de qualidade e validação. Após a validação, cada um dos autores do estudo codificou as transcrições separadamente no NVivo antes de comparar e discutir suas interpretações e códigos. Todos os dados foram compilados em uma linha do tempo linear que estabeleceu o ponto de partida de um processo final de codificação. Codificamos para pistas narrativas que apresentavam expressões da identidade, o que nos permitiu ver uma mudança no foco temporal ao longo do tempo.

\section{Achados}

Na seção seguinte, apresentamos nossos achados como uma sequência linear de eventos para dar conta de suas contingências (Sewell, 2005). Argumentamos que uma mudança gradual no foco temporal, por meio da qual a organização direciona cada vez mais sua atenção para o futuro, está ligada ao esquecimento organizacional e à diluição de identidade. Trazemos esse mecanismo para o primeiro plano, descrevendo uma série de eventos, transições e pontos de inflexão que instigaram essas mudanças. Mostramos como a diluição da identidade resulta de uma falha em continuamente integrar a experiência vivenciada na narrativa da identidade temporal; em seguida, demonstramos como uma mudança contínua no foco temporal permite um restabelecimento do equilíbrio identitário.

\section{Introdução: os primeiros anos}

A organização sem fins lucrativos estudada foi inaugura em 2006 como uma filial de um fornecedor comercial de kits de refeição orgânica. A organização recém-formada começou com o objetivo explícito de fortalecer o conhecimento das crianças sobre cultura alimentar, saúde e sustentabilidade, estabelecendo o que eles definiram como a "melhor sala de aula do mundo" (Manual Organizacional Interno, 2011). A organização sem fins lucrativos desenvolveu um conceito educacional baseado em oito módulos teóricos e práticos com três áreas de foco: jardinagem escolar, natureza e culinária ao ar livre (Manual Organizacional Interno, 2011). No início de sua operação, a organização estabeleceu uma colaboração contínua com o município local, o que ajudou a financiar as visitas regulares às escolas locais (quarto e quinto ano). Além disso, as doações de duas fundações ajudaram a financiar as operações iniciais. A organização sem fins lucrativos era administrada de forma ad-hoc e informal, administrada pelo fundador, um gerente e alguns instrutores de jardinagem trabalhando em meio período e voluntários (Ejlersen, 2019).

Como o conceito de hortas escolares foi bem-sucedido (Wistoft, 2013), entusiastas de jardinagem de municípios de todo o país logo entraram em contato com a organização para pedir ajuda para criar suas próprias hortas escolares locais. Para acomodar o interesse crescente, a organização solicitou financiamento de uma das maiores fundações da Dinamarca para iniciar uma disseminação nacional do conceito educacional em 2013 (Candidatura para financiamento, 2013). Em seu esforço para atrair suporte financeiro, a organização sem fins lucrativos enfatizou veementemente sua conexão com sua amplamente reconhecida empresa-mãe em sua candidatura para financiamento. Por meio de repetidas menções à empresamãe (16 vezes), a identidade da organização sem fins lucrativos permaneceu estreitamente narrada e conectada à de seu fundador. Enfatizando a relação sinérgica entre as duas organizações, a candidatura demonstra como a empresa-mãe representa uma parte indispensável do passado da organização sem fins lucrativos:

[A organização sem fins lucrativos] tem como base os mesmos fundamentos que [a empresa-mãe], o que tornou possível desenvolver o que agora constitui o conceito básico de [OSFL]. Existem persianas econômicas à prova d'água entre as duas organizações, mas ambas as organizações ganham por compartilhar o mesmo local. (Candidatura para financiamento, 2013, p.4)

Depois de obter o subsídio ( $€$ 1,3 milhões) para a qual se candidataram, a organização sem fins lucrativos estava pronta para embarcar no projeto iminente de implementação de hortas escolares em todo o país. No entanto, depois de receber o subsídio, o gerente da horta escolar saiu para buscar outras oportunidades, deixando a organização quase vazia.

Na verdade, o escritório ficou completamente vazio por 4 a 5 meses, enquanto eu, como presidente estava pensando: 'Uau!' Naquela época, tínhamos acabado de receber 10 milhões de coroas norueguesas [1,3 milhão de euros] [da fundação] que eram incertos. E tipo, o que eu faço? Com quem eu faço isso? (Entrevista do presidente, 2017) 
Para dar início à tarefa de implantar hortas escolares em todo o país, foi contratado um novo conjunto de funcionários em tempo integral: um gerente, um desenvolvedor de comunicações e dois instrutores de hortas escolares que se encarregaram de ensinar e desenvolver o conceito educacional. No entanto, os novos funcionários enfrentaram o desafio de construir alguns sistemas organizacionais básicos e rotinas para a organização nascente. A base informal em que a organização era administrada anteriormente deixava poucos traços mnemônicos (como documentos e procedimentos estabelecidos) para orientar os funcionários em sua narrativa de tarefa e identidade.

Percebi muito rápido que faltavam alguns sistemas básicos. E mesmo que não fosse minha especialidade nem nada, decidi me focar nisso, e foi a primeira coisa que fiz. $\mathrm{E}$ tentei construir isso. (Entrevista com um membro da equipe de gestão, 2017)

Com exceção do presidente do conselho de administração, que era um empreendedor serial com uma quantidade inesgotável de novas ideias, a rotatividade da organização fez com que não houvesse quem transmitisse a memória organizacional aos novos funcionários. Portanto, com a candidatura para subsídio como modelo, os funcionários recém-contratados começaram a construir uma nova narrativa da identidade organizacional, olhando para o futuro e dando sentido às promessas feitas nas candidaturas de projetos.

\section{Desenvolvimento: Crescimento em escala e escopo}

A mudança gradual no foco temporal se manifestou na expansão organizacional que se seguiu à obtenção do subsídio em 2013. Entre 2014 e 2016, o número de hortas escolares em todo o país cresceu de 7 para cerca de 30 (ver Figura 1). Esse crescimento coincidiu com a implementação de uma reforma escolar nacional em 2013, que, entre outras coisas, exigiu um maior foco nas ciências naturais, atividade física e horários escolares mais longos, mas mais flexíveis, tornando as hortas escolares uma excelente ferramenta para atender às novas demandas governamentais (Olsen \& Trier, 2013).

Além de aumentar o número de hortas escolares em todo o país, a organização sem fins lucrativos também desenvolveu uma série de novos projetos. Em vez de permanecer dentro dos limites da educação alimentar, a organização procurou explorar o interesse generalizado da sociedade em agendas sustentáveis e o número crescente de iniciativas verdes, expandindo a missão da organização:
Precisamos nos abrir para outras áreas relevantes. Não há o suficiente no campo educacional. (Entrevista com um membro da equipe de gestão, 2017)

\section{Figura 1. Número total de hortas escolares}

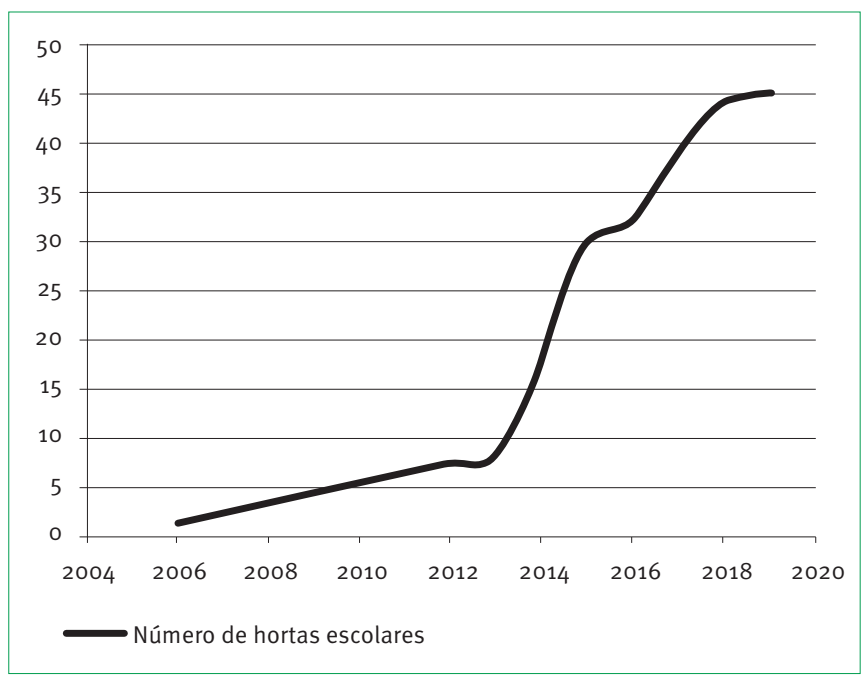

Se aproveitando da atenção recebida, a organização sem fins lucrativos gradualmente se viu em um ciclo de redação de candidaturas para financiar novas iniciativas, desenvolvendo novos conceitos e procedimentos, enquanto também tentava expandir o número de hortas escolares. A decisão de expandir a missão da organização a levou a se aventurar em outras áreas, tentando adaptar o conceito original de horta escolar para caber em outros contextos (por exemplo, habitação social). Esse desenvolvimento foi impulsionado ainda mais pelo modelo financeiro da organização sem fins lucrativos, que dependia de doações externas e tornava a organização vulnerável às demandas e expectativas de seus benfeitores. Como o financiamento das fundações é alocado principalmente para novas iniciativas, ao invés de manter as operações existentes, a organização sem fins lucrativos enfrentou um problema: para se manter em atividade, promessas de novas entregas tinham que ser feitas. Para manter a legitimidade e um relacionamento favorável com financiadores em potencial, a organização tomou decisões com base em suas esperanças de futuro, moldando a direção da organização de maneiras não intencionais:

Estou muito feliz que abrimos [para novas áreas], mas provavelmente não teríamos, se não fosse ... se não fosse a única maneira pela qual a fundação e outros nos apoiariam financeiramente novamente. (Entrevista com o presidente, 2017) 
Para lidar com a pressão contínua para obter novos financiamentos, a organização continuou a gerar novas ideias sobre como adaptar o conceito de horta escolar a outros ambientes. Uma dessas iniciativas foi desenvolver um livro de receitas para crianças com receitas inspiradoras que permitiriam às crianças expandir sua curiosidade culinária, conhecimento e habilidades em casa com suas famílias. Em 2015, 170.000 exemplares foram publicados e distribuídos gratuitamente, graças a uma doação adicional da fundação patrocinadora (€ 0,7 milhões / DKK 5,1 milhões). Para apoiar ainda mais essa iniciativa, a organização sem fins lucrativos inaugurou clubes de culinária infantil em todo o país. Outro projeto desenvolvido pela organização foi uma iniciativa que visava melhorar a qualidade de vida em comunidades de habitação social por meio da jardinagem social. Além disso, a organização sem fins lucrativos se comprometeu a criar uma plataforma digital de aprendizagem, um festival anual de comida, desenvolver cinco novos projetos-piloto e realizar um ciclo anual de atividades durante todo o ano (seminários, dias temáticos, etc.). Programas para estender o conceito de horta escolar a outras faixas etárias (por exemplo, jardins de infância, adolescentes e idosos aposentados) e a grupos vulneráveis (por exemplo, refugiados e pessoas com várias deficiências) também foram considerados como projetos em potencial. Um membro da organização explica:

Você não acreditaria em todas as coisas que já passamos. Temos visto de tudo, desde a conversão orgânica de municípios. [...] É louco! (Entrevista com um membro da equipe de gestão, 2017)

\section{Sequestrado por um futuro imaginado}

Tendo tentado separar sua narrativa da identidade daquela de seu fundador, a organização sem fins lucrativos tornou-se cada vez mais focada em seu potencial futuro ao invés de focar em suas realizações passadas. Depois de controlar sua identidade como uma organização sem fins lucrativos e silenciar seu passado, quase nenhuma referência foi feita à organização-mãe nas candidaturas de projetos enviadas após 2015. Em vez disso, a identidade da organização sem fins lucrativos tornou-se cada vez mais definida e subsidiada por seus projetos em andamento e aspirações futuras, as quais foram incentivadas e legitimadas por fundações de financiamento que preferiam que as menções explícitas ao passado da organização sem fins lucrativos fossem reduzidas ao mínimo (correspondência por e-mail, 2017). As conversas durante as reuniões e workshops demonstraram ainda mais como os membros da organização cada vez mais consideravam que sua tarefa principal era desenvolver novos projetos e não manter os empreendimentos anteriores. Nessas discussões, os membros da organização pareciam concordar que a missão original havia se tornado redundante, pois não abarcava a ampla gama de novas atividades e ambições organizacionais. Embora a missão tenha sido considerada "muito limitada" e "sem foco" (notas de campo, 2017), a administração teve dificuldade em articular as reivindicações da identidade atuais da organização. Quando questionados sobre as diferentes funções da organização, a maioria dos funcionários descreveu suas funções como principalmente relacionadas ao "desenvolvimento", ao mesmo tempo em que descrevem a organização como "uma desenvolvedora de ideias" (notas de campo, 2017). Essas noções formaram a base para a identidade organizacional emergente, que foi guiada por novas candidaturas de projeto, temporalmente localizadas no futuro, e quase completamente desligadas do passado.

O foco temporal no futuro da nova narrativa da identidade emergente refletiu-se ainda mais em como e quais tarefas a organização sem fins lucrativos realizava e priorizava. Consequentemente, inúmeras horas de trabalho e esforços foram dedicados à busca e identificação de novas possibilidades de financiamento e, subsequentemente, a elaboração de candidaturas de projetos para financiar potenciais iniciativas futuras. A busca contínua por novas ideias de projetos resultou em uma cultura que comparou "novo" a "bom" em detrimento das tarefas contínuas:

[As pessoas] realmente se animaram e falaram sobre todo esse 'desenvolvimento' e outras ideias que também podiam ser seguidas. E isso ... isso foi ... Dá para falar que o que acontece é que isso se infiltra na organização. É como se o que estou fazendo não fosse tão importante. Nem há ninguém que defina uma direção e a enquadre. E então é realmente difícil priorizá-la. (Entrevista com um membro da equipe de gestão, 2017)

A crescente atenção dada a novos projetos gradualmente mudou a perspectiva temporal da organização sem fins lucrativos para um futuro imaginado, à medida que as tarefas relacionadas ao desenvolvimento ganharam "destaque em termos de valor e prestígio" (correspondência por e-mail) entre os funcionários. Enquanto a gama de projetos se expandia e mais esforços eram investidos no desenvolvimento de novos projetos e candidaturas de financiamento, as operações em andamento foram gradualmente negligenciadas. Intensificado por uma cultura organizacional que celebrava a inovação e o desenvolvimento, 
as tarefas mundanas e as atividades no presente tinham menos prioridade. À medida que a organização se tornou cada vez mais voltada para o futuro, a narrativa da identidade que anteriormente subsidiava a missão e a identidade da organização sem fins lucrativos ficou em segundo plano:

Às vezes isso me intriga... Por que olhar para trás, para o que foi feito por mais de cem anos? Por que não olhar para frente e dizer: o que poderia ser fantástico? Então, quando as pessoas perguntam: 'De onde você tira todas essas ideias?' Eu digo: 'Nós olhamos para frente! Com o que sonhamos? ' (Entrevista do presidente, 2017)

À medida que a organização foi sendo gradualmente definida pelo seu potencial futuro, novos projetos começaram a constituir novos marcadores da identidade organizacional. A transferência do conceito de horta escolar para outros contextos revelou-se muito mais problemática do que era inicialmente esperado, pois foi desafiador adquirir conhecimento suficiente para transferir e adaptar o conceito a outras áreas. Embora a organização tenha descrito sua cultura como sendo caracterizada por "muita energia" e "funcionários dedicados", seu foco no desenvolvimento de novos projetos havia desviado a organização de sua missão original. À medida que a identidade da organização sem fins lucrativos se diluía e um vácuo da identidade emergia, uma nova narrativa da identidade era necessária para criar coerência e dar sentido a todos os projetos divergentes que estavam em desenvolvimento:

(...) é necessário um fio condutor claro em todas as nossas iniciativas. Mesmo você achando que pode estar um pouco mais longe do núcleo, é necessária uma linha comum clara. (Entrevista com um membro da equipe de gestão, 2017)

A nova narrativa da identidade emergente era uma história sobre uma organização em que o "desenvolvimento" era o coração de sua identidade. Essa mudança na autopercepção levou à diluição da identidade, onde a missão original da organização foi sequestrada por seu futuro imaginado.

\section{Lidando com a diluição da identidade e desvio da missão}

Com o tempo, uma nova consciência foi emergindo entre os funcionários, a de que a organização sem fins lucrativos havia se desviado de seu caminho original, o que resultou em confusão sobre a identidade e a direção estratégica da organização. Um funcionário se lembra de ter pensado o seguinte:

Há algo errado aqui. Ninguém se atreveu a dizer que havia algo de errado na maneira como nos organizamos [como organização] e isso nunca foi mencionado. (Entrevista com um membro da equipe de gestão, 2017)

A incerteza quanto ao propósito e missão da organização fez emergir questões da identidade: Ainda somos uma organização de hortas escolares e, se não, o que somos? Estava em jogo a identidade e a memória da organização sobre "quem somos e de onde viemos".

O que percebi foi que ninguém tinha uma visão geral sobre o que estava acontecendo. Simplesmente não tinha quando eu cheguei. (Entrevis ta com um membro da equipe de gestão, 2017)

A crescente frustração com a identidade entre os membros de organizações sem fins lucrativos atingiu seu auge no início do verão de 2017. Os esforços para lidar com a crescente insatisfação resultaram em duas demissões, uma transição gerencial e mudanças na equipe da alta administração. Um novo gerente principal, que anteriormente supervisionava o contato com as hortas da escola local, foi recrutado internamente. A transição significou uma mudança no estilo de gestão e um foco estrito nas tarefas principais. Como resultado, onze projetos antecipados ficaram presos em um "limbo de desenvolvimento" (correspondência por e-mail).

Antes a equipe de desenvolvimento era a coisa mais importante do mundo, agora somos uma função de apoio. (Entrevista com um membro da equipe de gestão, 2017)

Assim, a mudança implicou em um tipo de abordagem de volta ao básico, no sentido de que a organização sem fins lucrativos se redescobriu como uma organização de horta escolar, realinhando assim sua identidade e foco temporal.

Acho que estamos no caminho certo agora. Estamos realmente focados no negócio principal, que é a parte de horta escolar. (Entrevista com um membro da equipe de gestão, 2017) 
Como resultado desse realinhamento, a organização sem fins lucrativos também tomou conhecimento de seus ativos de memória interna, reconhecendo como seus membros mais duradouros eram o verdadeiro fio condutor e portadores da identidade na organização. Por meio de uma série de reuniões, a organização passou a revisitar seu passado relativamente curto em busca de sua identidade. Ao examinar seu passado, a organização sem fins lucrativos tomou conhecimento de uma história mais ampla das hortas escolares que se estendia para além do que eles imaginavam. Dessa forma, a organização sem fins lucrativos redefiniu e estendeu sua história ao reconhecer como fazia parte de um movimento mais amplo e antigo de hortas escolares. A organização expandiu sua perspectiva histórica para encapsular uma história mais distante, não mais apenas se referindo ao seu próprio passado fundador. No entanto, estender seu horizonte temporal não afetou apenas a conceitualização da organização sobre seu passado, mas também permitiu que vislumbrassem seu futuro. A organização expandiu seu horizonte futuro, passando de horizontes temporais focados no futuro próximo, definidos por cada período de financiamento do projeto, para adotar a Agenda de Desenvolvimento Sustentável das Nações Unidas 2030 como sua missão. Essa ampliação dos horizontes do passado-futuro reforçou ainda mais a importância da sua missão original e tarefa central: "fortalecer o compromisso de crianças e jovens com a sustentabilidade, cultura alimentar e saúde" (Tradução dos autores do texto encontrado no site). O Quadro 2 fornece uma visão geral das mudanças no foco temporal.

\section{Quadro 2. Mudanças no foco temporal marcadas por eventos, transições e pontos de inflexão}

\begin{tabular}{|c|c|c|}
\hline Ano & Grandes eventos, transições e pontos de inflexão & Foco temporal \\
\hline 2003 & $\begin{array}{l}\text { O fundador da organização sem fins lucrativos inicia atividades no terreno da empresa que mais } \\
\text { tarde evoluiriam para a organização sem fins lucrativos }\end{array}$ & Presente \\
\hline 2006 & A organização sem fins lucrativos é estabelecida. & Presente - futuro \\
\hline 2013 & $\begin{array}{l}\text { Financiamento do lote principal obtido. A empresa fundadora foi mencionada } 16 \text { vezes na } \\
\text { candidatura. Descrito como um relacionamento próximo e sinérgico } \\
\text { Foco no reconhecimento externo e na legitimidade (local) }\end{array}$ & $\begin{array}{l}\text { Orientação passado- } \\
\text { presente-futuro }\end{array}$ \\
\hline 2014 & $\begin{array}{l}\text { Rotatividade total na organização. Novas contratações (sem experiência vivenciada do passado } \\
\text { organizacional). }\end{array}$ & Orientação presente-futuro \\
\hline 2015 & Novo(s) projeto(s) adicionado(s) ao portfólio. & Orientação futura \\
\hline 2017 & $\begin{array}{l}\text { Workshops iniciados. } \\
\text { Desejo expresso de se concentrar ainda mais no desenvolvimento. Visão expressa como sendo } \\
\text { muito focada nas crianças. Necessidade de encontrar o núcleo da organização; um desenvolvedor } \\
\text { de ideias e conceitos? } \\
\text { Promessa de estabelecer mais cinco projetos piloto } \\
\text { Novos funcionários desconhecem o passado organizacional } \\
\text { Alta administração demitida } \\
\text { Os objetivos de desenvolvimento da ONU e a história da horta escolar tornam-se parte da narrativa } \\
\text { da identidade }\end{array}$ & $\begin{array}{l}\text { para passado-presente- } \\
\text { futuro } \\
\text { para orientação de longo } \\
\text { prazo passado-presente- } \\
\text { futuro }\end{array}$ \\
\hline
\end{tabular}




\section{DISCUSSÃO}

Ao longo desse artigo, ilustramos como um foco temporal unilateral no futuro que emerge instigado por uma série de ações e eventos resultou na perda da memória organizacional e diluição da identidade organizacional. Esse processo foi impulsionado por uma preocupação exagerada com o desenvolvimento para concretizar um futuro esperado, o que, por sua vez, teve consequências para a identidade organizacional. Argumentamos que o esquecimento organizacional pode levar à criação de narrativas de identidade fracamente acopladas que sequestram e deslocam a identidade e missão originais da organização. Outros fatores, como alta rotatividade de funcionários e pressões de benfeitores externos dos quais a organização depende financeiramente para garantir a sua operação contínua, alimentam ainda mais esse processo. Consequentemente, essas condições precárias induzem um foco excessivo em projetos organizacionais orientados para o futuro e uma menor atenção às operações passadas (e presentes). Por estar excessivamente preocupada em agradar os stakeholders externos, a organização gera um vácuo da identidade, por meio do qual uma narrativa organizacional recém-construída se torna uma ferramenta de remendo para construir coerência entre projetos organizacionais novos e em andamento. Interpretando nossos resultados em relação à teoria existente, notamos como as narrativas assumem um papel performativo nos processos de construção da identidade (Maclean et al., 2015). Contribuímos para as discussões anteriores sugerindo que as narrativas de identidade emergentes que reivindicam um foco temporal consistente e unidirecional tendem a se amplificar e a se alimentar mutuamente, aumentando o risco de diluição da identidade. Embora as organizações tenham agência temporal (Emirbayer \& Mische, 1998), mostramos como elas podem não a exercer deliberadamente. Nossos resultados sugerem que a memória organizacional não é apenas um recurso estratégico para a construção de identidade (Foster et al., 2011), mas também uma âncora temporal que mantém a ambição futura sob controle (Maclean et al., 2018).

Desde o início, consideramos a lembrança e o esquecimento como dois lados da mesma moeda, dos quais dependem as narrativas que subsidiam a identidade organizacional, incluindo e excluindo elementos do passado organizacional e de campo (Foster et al., 2011). Pesquisas anteriores sobre esquecimento organizacional concentraram-se em grande parte na ação intencional e no potencial estratégico do esquecimento, no qual as organizações omitem ou selecionam conscientemente elementos do passado para permitir a coerência, autenticidade e legitimidade de sua identidade (por exemplo, Anteby \& Molnár, 2012; Foster et al., 2017; Hatch \& Schultz, 2017). Nesses estudos, o esquecimento organizacional é em grande parte visto como uma decisão estratégica, na qual a alta administração omite elementos particulares do passado da organização para construir e promover uma identidade desejada e uma direção estratégica específica. Embora concordemos com esses argumentos, nosso estudo contribui para um aspecto menos examinado do esquecimento organizacional, focando na ação não intencional e nas consequências de silenciar ou esquecer o passado. Além disso, estudos anteriores mostram como as organizações promovem esquecimento intencional (Mena et al., 2016) e enfatizam como as organizações manipulam o que é lembrado (Anteby \& Molnár, 2012). Assim, presumem que à medida que algumas memórias são silenciadas, outras são mobilizadas em seu lugar. No entanto, nosso caso demonstra como o passado organizacional é silenciado e esquecido por completo. Isso é confirmado pelo estudo de Maclean et al. (2017) sobre a transição da identidade dos alemães orientais à medida que faziam a transição para uma Alemanha reunificada e sua identidade original foi sequestrada e deslocada pela identidade da Alemanha Ocidental. Portanto, entendemos a pesquisa sobre memória organizacional, destacando como o foco temporal constitui um mecanismo chave para a lembrança organizacional e construção da identidade. Teorizamos uma ligação entre o foco temporal, a memória organizacional e a identidade, mostrando como uma série de eventos (não intencionais), transições e momentos decisivos influenciam e moldam a organização. Nossa contribuição está no esquecimento, não apenas como escolha estratégica e resultado de ação deliberada (Mena et al., 2016), mas também como efeitos não intencionais de uma série de ações e decisões tomadas em decorrência da dependência financeira da organização de financiamento externo, práticas de recrutamento, rotatividade organizacional, crescimento organizacional, inclinação cultural e uma orientação estratégica voltada para o desenvolvimento e inovação.

Nosso estudo confirma as descobertas anteriores de Easterby-Smith e Lyles (2011), que argumentam que a alta rotatividade organizacional pode levar ao esquecimento organizacional e à diluição da identidade. Nossos achados sugerem que as narrativas do passado são esquecidas devido ao rápido crescimento e à rotatividade de pessoal, a qual é caracterizada por uma mudança quase completa na equipe organizacional. Nosso caso ilustra como a organização sem fins lucrativos envolvida no trabalho da identidade para estabelecer independência de sua organização-mãe na tentativa de definir e dar sentido a sua identidade e missão. Envolvendo-se nesse 
tipo de trabalho, os membros da organização fazem uso de tecnologias mnemônicas (Olick, 1999) como um substituto para a narrativa da identidade anterior e a memória que a conectava à organização original. Em um esforço para estabelecer uma nova identidade, alterando o estreito vínculo histórico entre a empresa controladora e a organização sem fins lucrativos, a organização sem fins lucrativos mudou sua orientação temporal e foco para o futuro estabelecendo a candidatura para financiamento - com ênfase no desenvolvimento organizacional - como um novo marcador da identidade. Nossas descobertas demonstram ainda como a realização bem-sucedida de novos (futuros) projetos faz com que a organização esqueça seu passado, levando assim a um desvio de missão .

Além disso, devido à estrutura sem fins lucrativos da organização, ela permanece altamente dependente de financiamento externo e, portanto, altamente vulnerável às demandas de seus benfeitores externos (Santos, Pache, \& Birkholz, 2015). Consequentemente, essas relações precárias levam a um foco excessivo em projetos organizacionais orientados para o futuro e uma menor atenção às operações passadas e em andamento, o que resulta em hiperadaptação (Hatch \& Schultz, 2002). 0 resultado dessa perspectiva temporal unilateral, que se concentra em grande parte no futuro, é ainda refletido e apoiado por uma cultura organizacional em que o "novo" é igualado ao "bom". Essa perspectiva temporal faz com que a administração negligencie revisitar as questões básicas e importantes de "quem somos" (Albert \& Whetten, 1985) e "de onde viemos?" (Gioia, Schultz, \& Corley, 2000), o que por sua vez estimula uma reação negativa contra a identidade da organização. Portanto, nossas descobertas sugerem que em tempos de mudança, o trabalho de identidade é fundamental para a sobrevivência de uma organização. Nossos resultados também confirmam pesquisas anteriores, mostrando como o passado é usado para o futuro (Schultz \& Hernes, 2013). Dessa forma, o passado, o presente e o futuro são entidades inseparáveis que estão inerentemente ligadas (Emirbayer \& Mische, 1998). Ilustramos os três estágios de busca e diluição de identidade e mudanças no foco temporal na Figura 2.

\section{Número de hortas escolares}

Figura 2. Foco temporal e estágios de busca e diluição de identidade

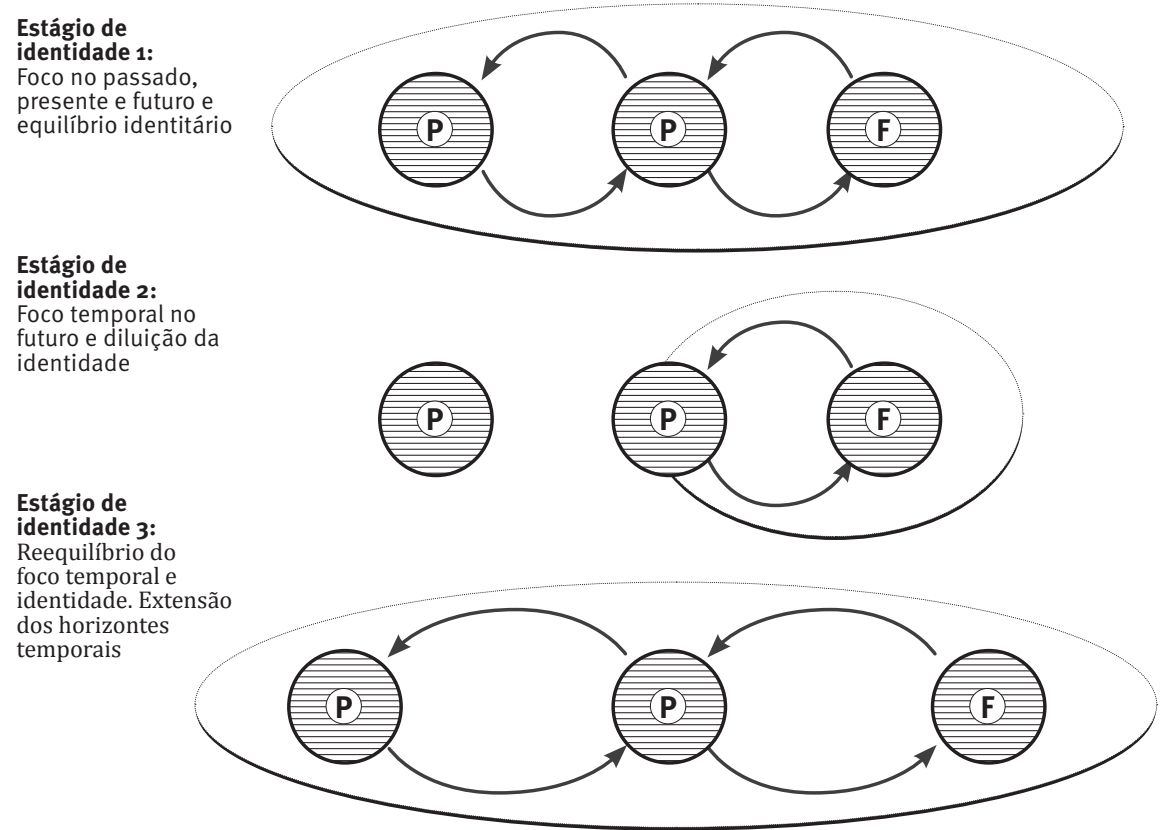


Verificamos que o passado não é apenas um recurso de identidade estratégica para construir autenticidade e legitimidade (Hatch \& Schultz, 2017), mas, assim como afirmado por Maclean et al. (2018), é também uma âncora temporal a partir da qual a organização pode buscar seu propósito, evitar a diluição de identidade e se preparar para mudanças futuras.

\section{CONSIDERAÇÕES FINAIS}

Nosso estudo contribui para a literatura sobre narrativas temporais como forças construtoras de identidade, e os resultados do estudo fornecem insights sobre o poder e os mecanismos em torno de tais narrativas. Embora as narrativas temporais possam ser empregadas como ferramentas retóricas para construir coerência temporal entre diferentes ações organizacionais, afirmamos que elas também têm o potencial de "sequestrar" a direção organizacional. Sugerimos que organizações orientadas para o presente e o futuro estão mais sujeitas a isso, pois silenciar o passado (Maclean et al., 2017) e esquecer sua história pode distorcer a missão pretendida da organização. Por estar excessivamente preocupada em agradar os stakeholders externos, a organização gera hiperadaptação (Hatch \& Schultz, 2002), o que leva à diluição da identidade e a um vácuo da identidade. A narrativa organizacional recém-construída torna-se uma ferramenta de remendo para criar coerência em todo o portfólio com cada vez mais novos projetos organizacionais. No entanto, essas novas narrativas podem gradualmente sequestrar e substituir a missão organizacional original. Sugerimos que as organizações podem ser menos propensas a hiperadaptação, diluição de identidade e desvio de missão ao adotar uma visão de longo prazo (Maclean et al., 2018) e prever passados $e$ futuros distantes ao se tornarem menos sensiveis a mudanças nos gostos e demandas externas do campo. No entanto, nosso estudo também mostra que a identidade organizacional pode ser restaurada ao revisitar e lembrar o passado. Dessa forma, nosso estudo também demonstra os mesmos efeitos habilitadores do passado para resiliência organizacional e sobrevivência mostrados em outros estudos (por exemplo, Anteby \& Molnár, 2012; Foster et al., 2011; Schultz \& Hernes, 2013). No entanto, sugerimos que o passado da organização não é apenas um recurso estratégico para a construção da identidade, é também uma âncora temporal a partir da qual a organização pode buscar seu propósito e se preparar para mudanças futuras. Por fim, sugerimos que uma organização deve ser capaz de equilibrar seu foco temporal e olhar para o futuro imaginado, ao mesmo tempo em que se lembra do passado.

\section{AGRADECIMENTOS}

Uma versão inicial do texto foi apresentada na conferência LAEMOS em Buenos Aires e versões posteriores deste trabalho foram apresentadas na Conferência SCANCOR-Weatherhead na Universidade de Harvard e também, no EGOS na área "Organization \& Time" em Edimburgo. Agradecemos todos os feedbacks recebidos em todas as conferências e também, aos Editores Convidados dessa chamada e aos dois avaliadores, que nos ajudaram no enquadramento teórico do texto. Um agradecimento especial aos nossos colegas Joanne Geraldi e José Ossandón pela tradução de nossos resumos para o português e espanhol, respectivamente. Por fim, gostaríamos de agradecer à liderança e aos membros da organização sem fins lucrativos por nos conceder acesso à sua organização e dedicar parte de seu tempo a este estudo.

\section{REFERÊNCIAS}

Albert, S., \& Whetten, D. A. (1985). Organizational identity. Research in Organizational Behavior, 7, 263-295.

Anteby, M., \& Molnár, V. (2012). Collective memory meets organizational identity: Remembering to forget in a firm's rhetorical history. Academy of Management Journal, 55(3), 515-540. doi: 10.5465/ amj.2010.0245

Blaschke, S., \& Schoeneborn, D. (2006). The forgotten function of forgetting: Revisiting exploration and exploitation in organizational learning. Soziale Systeme, 12(1), 100-120. doi: 10.1515/sosys-2006-0107 |

Bluedorn, A. C. (2002). The human organization of time: Temporal realities and experience. Stanford, California: Stanford University Press

Boje, D. M. (2008). Storytelling organizations. Thousand Oaks, California: Sage.

Bone, R. G. (2007). Schechter's ideas in historical context and dilution's rocky road. Santa Clara High Technology Law Journal, 24(3), 469-506.

Booth, C., Clark, P., Delahaye, A., Procter, S., \& Rowlinson, M. (2007). Accounting for the dark side of corporate history: Organizational culture perspectives and the Bertelsmann case. Critical Perspectives on Accounting, 18(6), 625-644. doi: 10.1016/j.cpa.2007.03.012

Brown, R., \& Kulik, J. (1977). Flashbulb memories. Cognition, 5(1), 73-99.

Brunsson, N. (2009). Reform as routine: Organizational change and stability in the modern world. Oxford, UK: Oxford University Press 
Cappelen, S.M. and Strandgaard Pedersen, J. (2020). Inventing Culinary Heritage through Strategic Historical Ambiguity. Organization Studies. doi: 10.1177/0170840620918382

Clark, L. F., \& Collins, J. E. (1993). Remembering old flames: How the past affects assessments of the present. Personality and Social Psychology Bulletin, 19, 399-408. doi: 10.1177/0146167293194005

Corley, K. G., \& Gioia, D. A. (2004). Identity ambiguity and change in the wake of a corporate spin-off. Administrative Science Quarterly, 49(2), 173-208. doi: 10.2307/4131471

Dailey, S. L., \& Browning, L. (2014). Retelling stories in organizations: Understanding the functions of narrative repetition. Academy of Management Review, 39(1), 22-43. doi: 10.5465/amr.2011.0329

Dogan, S. L. (2006). What is dilution, anyway? Michigan Law Review First Impressions, 105, 103-107.

Easterby-Smith, M., \& Lyles, M. A. (2011). In praise of organizational forgetting. Journal of Management Inquiry, 20(3), 311-316. doi: $10.1177 / 1056492611408508$

Ejlersen, S. (2019). Dyrk Livet: Skolehaver, klimatanker og fornyet jordforbindelse. Copenhague, Denmark: Peoples Press.

Emirbayer, M., \& Mische, A. (1998). What is agency? American Journal of Sociology, 103(4), 962-1023.

Ezzy, D. (1998). Theorizing narrative identity: Symbolic interactionism and hermeneutics. Sociological Quarterly, 39(2), 239-252. doi: 10.1111/j.1533-8525.1998.tboo502.x

Fine, G. A. (Ed.). (2012). Sticky reputations: The politics of collective memory in midcentury America. New York, NY: Routledge.

Foster, W. M., Coraiola, D. M., Suddaby, R., Kroezen, J., \& Chandler, D. (2017). The strategic use of historical narratives: A theoretical framework. Business History, 59(8), 1176-1200. doi: 10.1111/j.15338525.1998.tboo502.x

Foster, W. M., Suddaby, R., Minkus, A., \& Wiebe, E. (2011). History as social memory assets: The example of Tim Hortons. Management \& Organizational History, 6(1), 101-120. doi:10.1177/1744935910387027

Gioia, D. A., Schultz, M., \& Corley, K. G. (2000). Organizational identity, image, and adaptive instability. Academy of Management Review, 25(1), 63-81. doi: 10.2307/259263

Halbwachs, M. (1992). On collective memory. Chicago, Illinois: University of Chicago Press.

Hatch, M. J., \& Schultz, M. (2002). The dynamics of organizational identity. HumanRelations,55(8),989-1018. doi:10.1177/0018726702055008181

Hatch, M. J., \& Schultz, M. (2017). Toward a theory of using history authentically: Historicizing in the Carlsberg Group. Administrative Science Quarterly, 62(4), 657-697. doi: 10.1177/0001839217692535
Heisler, M. O. (2008). Introduction: The political currency of the past: History, memory, and identity. The ANNALS of the American Academy of Political and Social Science, 617(1), 14-24. doi: 10.1177/0002716208315024

Henriksen, L. S., \& Bundesen, P. (2004). The moving frontier in Denmark: Voluntary-state relationships since 1850. Journal of Social Policy, 33(4), 605-625. doi: 10.1017/So047279404008025

Henriksen, L. S., Strømsnes, K., \& Svedberg, L. (2018). Civic engagement in Scandinavia. Volunteering, informal help and giving in Denmark, Norway and Sweden. Springer. Cham, Germany

Holan, P. M. De, \& Phillips, N. (2004). Organizational forgetting as strategy. Strategic Organization, 2(4), 423-433.

Kraft \& Partners. (2019). Den Danske Fondsanalyse 2019. Analyse af fonde med almennyttige uddelinger i Danmark. Kraft \& Partners.dk

Kreiner, G. E., Hollensbe, E., Sheep, M. L., Smith, B. R., \& Kataria, N. (2015). Elasticity and the dialectic tensions of organizational identity: How can we hold together while we are pulling apart? Academy of Management Review, 58(4), 981-1011. doi: 10.5465/amj.2012.0462

Kunisch, S., Bartunek, J. M., Mueller, J., \& Huy, Q. N. (2017). Time in strategic change research. Academy of Management Annals, 11(2), 1005-1064. doi: 10.5465/annals.2015.0133

Lippmann, S., \& Aldrich, H. E. (2016). A rolling stone gathers momentum: Generational units, collective memory, and entrepreneurship. Academy of Management Review, 41(4), 658-675. doi: 10.5465/amr.2014.0139

Maclean, M., Harvey, C., Gordon, J., \& Shaw, E. (2015). Identity, storytelling and the philanthropic journey. Human Relations, 68(10), 1623-1652. doi: 10.1177/0018726714564199

Maclean, M., Harvey, C., Sillince, J. A. A., \& Golant, B. D. (2018). Intertextuality, rhetorical history and the uses of the past in organizational transition. Organization Studies, 39(12), 1733-1755. doi: $10.1177 / 0170840618789206$

Maclean, M., Harvey, C. \& Stringfellow, L.J.(2017). Narrative, metaphorand the subjective understanding of historic identity transition. Business History, 59(8), 1218-1241. doi: 10.1080/00076791.2016.1223048

Madsen, P. M. (2009). These lives will not be lost in vain: Organizational learning from disaster in US coal mining. Organization Science, 20(5), 861-875. doi: 10.1287/orsc.1080.0396

Marginson, D., \& McAulay, L. (2008). Exploring the debate on shorttermism: A theoretical and empirical analysis. Strategic Management Journal, 29(3), 273-292. doi: 10.1002/smj.657

Mena, S., Rintamäki, J., Fleming, P., \& Spicer, A. (2016). On the forgetting of corporate irresponsibility. Academy of Management Review, 41(4), 720-738. doi: 10.5465/amr.2014.0208

Nadkarni, S., \& Chen, J. (2014). Bridging yesterday, today, and tomorrow: CEO temporal focus, environmental dynamism, and rate of new product introduction. Academy of Management Journal, 57(6), 1810-1833. doi: 10.5465/amj.2011.0401 
Olick, J. K. (1999). Collective memory: The two cultures. Sociological Theory, 17(3), 333-348. doi: 10.1111/0735-2751.00083

Olick, J. K., \& Robbins, J. (1998). Social memory studies: From “collective memory" to the historical sociology of mnemonic practices. Annual Review of Sociology, 24(1), 105-140. doi: 10.1146/annurev.soc.24.1.105

Olsen, J. V., \& Trier, M. B. (2013). Ny folkeskolereform virker fra august 2014, Folkeskolen.dk. June 13, 2013.

Reinecke, J., \& Ansari, S. (2016). Time, temporality and process studies. In A. Langley, \& H. Tsoukas (Eds.), The Sage handbook of process organization studies (pp. 402-416). London, UK: Sage.

Rowlinson, M., Casey, A., Hansen, P. H., \& Mills, A. J. (2014). Narratives and memory in organizations. Organization, 21(4), 441-446. doi: $10.1177 / 1350508414527256$

Santos, F. M., Pache, A., \& Birkholz, C. (2015). Making hybrids work: Aligning business models and organizational design for social enterprises. California Management Review, 57(3), 36-58. doi: $10.1525 / \mathrm{cmr} .2015 \cdot 57 \cdot 3 \cdot 36$

Schechter, F. I. (1927). The rational basis of trademark protection. Harvard Law Review, 40, 813. doi: 10.2307/1330367

Schultz, M., \& Hernes, T. (2013). A temporal perspective on organizational identity. Organization Science, 24(1), 1-21. doi: 10.1287/ orsc.1110.0731
Sewell, W. H., Jr. (2005). Logics of history: Social theory and social transformation. University of Chicago, Illinois: Chicago Press.

Shipp, A. J., Edwards, J. R., \& Lambert, L. S. (2009). Conceptualization and measurement of temporal focus: The subjective experience of the past, present, and future. Organizational Behavior and Human Decision Processes, 110(1), 1-22. doi: 10.1016/j.obhdp.2009.05.001

Suddaby, R., Foster, W. M., \& Quinn-Trank, C. (2016). Organizational re-membering: Rhetorical history as identity work. In M. G. Pratt, M. Schultz, B. E. Ashforth, \& D. Ravasi (Eds.), The Oxford Handbook of Organizational Identity (pp. 297-316). Oxford, UK: Oxford University Press.

Walsh, J. P., \& Ungson, G. R. (1991). Organizational memory. Academy of Management Review, 16(1), 57-91. doi: 10.5465/amr.1991.4278992

Wilkins, A. L., \& Bristow, N. J. (1987). For successful organization culture, honor your past. Academy of Management Perspectives, 1(3), 221229. doi: 10.5465 /ame.1987.4275745

Wistoft, K. (2013). The desire to learn as a kind of love: Gardening, cooking, and passion in outdoor education. Journal of Adventure Education \& Outdoor Learning, 13(2), 125-141. doi: 10.1080/14729679.2012.738011

Ybema, S. (2010). Talk of change: Temporal contrasts and collective identities. Organization Studies, 31(4), 481-503. doi: 10.1177/0170840610372205

\section{CONTRIBUIÇÃO DOS AUTORES}

Os autores declaram que participaram de forma conjunta na revisão final do texto, mas individualmente trabalharam na conceitualização e abordagem teórica-metodológica, bem como na revisão teórica (levantamento de literatura), coleta de dados, bem como na análise de dados e, por fim, redação e revisão final do artigo. 